\title{
Configurações
}

Revista de sociologia

\section{Ainda e sempre uma "classe-objeto"? Breve reflexão crítica sobre o papel consignado às populações locais pelas políticas de promoção da "multifuncionalidade" dos territórios rurais}

Still and always an "object-class"? Brief critical reflection on the role assigned to local populations by policies promoting the "multifunctionality" of rural areas Encore et toujours une "classe-objet»? Brève réflexion critique sur le rôle assigné aux populations locales par les politiques de promotion de la «multifonctionnalité» des territoires ruraux

João Queirós

\section{(2) OpenEdition}

\section{Edição electrónica}

URL: http://journals.openedition.org/configuracoes/1689

DOI: $10.4000 /$ configuracoes. 1689

ISSN: 2182-7419

Editora

Centro de Investigação em Ciências Sociais

\section{Edição impressa}

Data de publição: 1 Junho 2013

Paginação: 11-23

ISBN: 1646-5075

ISSN: 1646-5075

Refêrencia eletrónica

João Queirós, « Ainda e sempre uma "classe-objeto"? Breve reflexão crítica sobre o papel consignado às populações locais pelas políticas de promoção da "multifuncionalidade" dos territórios rurais », Configurações [Online], 11 | 2013, posto online no dia 22 setembro 2014, consultado o 19 abril 2019 URL : http://journals.openedition.org/configuracoes/1689; DOI : 10.4000/configuracoes.1689 


\section{Ainda e sempre uma "classe- objeto"? Breve reflexão crítica sobre o papel consignado às populações locais pelas políticas de promoção da "multifuncionalidade" dos territórios rurais}

Still and always an "object-class"? Brief critical reflection on the role assigned to local populations by policies promoting the "multifunctionality" of rural areas Encore et toujours une "classe-objet»? Brève réflexion critique sur le rôle assigné aux populations locales par les politiques de promotion de la «multifonctionnalité» des territoires ruraux

João Queirós

\section{Introdução}

1 Apesar da fraca produtividade que sempre evidenciou, a agricultura portuguesa deteve, até mais tarde do que a maioria das suas congéneres europeias, incluindo da Europa do Sul, uma forte importância empregadora, por um lado, e uma grande relevância na estruturação da economia e sociedade de vastas regiões do território nacional, por outro ${ }^{1}$.

Com efeito, o abandono da atividade agrícola é, em Portugal, um fenómeno relativamente recente. Em 1960, o número de total de explorações rondava ainda 830000 e a agricultura mantinha o estatuto de principal atividade empregadora, ocupando cerca de $44 \%$ dos ativos com profissão do país. 
3 A situação começará a alterar-se a partir dessa altura. O fortíssimo crescimento da emigração e do êxodo rural - este último associado ao progresso (muito "litoralizado") da industrialização do país - reduzirá, ao longo dos dez anos subsequentes, em cerca de 450 mil indivíduos o efetivo de ativos agrícolas e levará ao desaparecimento de cerca de 5\% do total de explorações - um fenómeno com especial incidência no Norte e Centro do país, onde se localizava a maioria das explorações abandonadas nos anos 1960.

4 As décadas seguintes, em especial os últimos vinte anos, serão de generalizado aprofundamento deste processo. O facto de, na maior parte dos casos, a agricultura portuguesa estar estruturada com base em sistemas de produção tradicionais, que se revelam desajustados face aos rigores e exigências de mercados de bens agrícolas funcionando em condições de crescente produtividade e concorrência, associado aos incipientes esforços de reorganização e modernização da atividade, redundou na inviabilização económica de milhares de explorações. Com efeito, a agricultura foi-se transformando, de dia para dia, numa atividade cada vez menos rentável e, por isso, menos atrativa, levando os mais jovens a abandonar o trabalho nos campos e a integrar as fileiras da indústria ou do cada vez mais relevante setor dos serviços.

5 O período compreendido entre 1989 e 2009 foi, sem surpresa, de fortíssimo abandono da atividade. Perto de 250 mil explorações desapareceram, de um total de 550 mil, e a população agrícola familiar diminuiu 37,5\% entre 1989 e 1999 e 36\% entre 1999 e 2009, correspondendo no ano terminal do período considerado a cerca de 790 mil pessoas. 0 seu peso no total da população portuguesa ronda agora os 7\%; em 1989, esse valor ascendia a 20\%. Tomando em consideração já não os dados referentes aos membros das famílias residentes em explorações agrícolas, mas apenas os números dos ativos com profissão, verificamos que, em 2011 (dados do Recenseamento Geral da População), apenas 3\% da população portuguesa empregada exerciam atividade no chamado "setor primário" da economia. $\mathrm{O}$ facto de, em 2009, perto de metade dos produtores agrícolas recenseados ter mais de 65 anos diz bem do fraco potencial de renovação da mão de obra agrícola portuguesa e dos limitados horizontes de desenvolvimento com que esta atividade parece ter de se confrontar. E apesar de a área agrícola utilizada não ter diminuído significativamente, verificando-se inclusivamente um aumento da dimensão média das explorações, o crescimento do peso das pastagens pobres indicia a extensificação ou abandono de vastas áreas outrora consagradas às culturas arvenses².

6 Neste quadro de "incontornável" ou "irreversível" declínio da agricultura, emergem novos discursos remetendo para configurações dos territórios rurais não exclusivamente ou não diretamente ligadas à produção agroflorestal. No "mosaico de atividades do mundo rural" cabem ainda a agricultura e a pecuária, sobretudo se desenvolvidas de forma "biológica", mas o protagonismo é cada vez mais do turismo, da gastronomia, dos serviços de animação e lazer, do artesanato e das atividades de preservação e gestão do património natural (Neves, 2008).

7 Retomando a linha de raciocínio proposta por Pierre Bourdieu num artigo publicado originalmente no final da década de 1970 - um texto entretanto tornado clássico da sociologia no qual o sociólogo francês discorre sobre o carácter heteronomamente determinado da produção e difusão das imagens, representações, identidades e projetos associados aos campos e aos camponeses (Bourdieu, 1977) -, o que neste artigo se propõe é uma reflexão crítica muito breve acerca das transformações que, num cenário crescentemente "pós-agrícola", a noção de "ruralidade" tem vindo a conhecer e do papel que, no quadro dessas transformações, é consignado às populações locais, 
designadamente àquelas que mantêm relação com a agricultura, pelo discurso da "multifuncionalidade", que nos últimos anos se vem assumindo como narrativa dominante no que ao "futuro", "viabilidade" e "desenvolvimento sustentável" dos territórios rurais diz respeito.

\section{0 abandono da atividade agrícola e as transformações na noção de "ruralidade"}

8 Ainda que recentemente os discursos em torno de um "desejável" ou mesmo "inevitável" regresso à agricultura tenham adquirido algum espaço político-mediático ${ }^{3}$, a verdade é que não será de esperar nos próximos tempos uma inversão das tendências que têm caracterizado a evolução deste setor nas últimas décadas. A estrutura fundiária característica da maior parte do espaço agrícola português, o elevado grau de envelhecimento dos produtores, os baixos níveis de produtividade, a feroz concorrência internacional e os condicionamentos impostos pelas políticas comunitárias no que concerne quer à produção, quer à própria definição das políticas nacionais são fatores que ajudam a sustentar tal prognóstico.

9 Apesar de se ouvir falar frequentemente em "apoios" e "incentivos" à agricultura e de as referências aos "fundos comunitários" destinados a este setor da economia fazerem parte do imaginário nacional há mais de vinte anos, a verdade é que as diversas medidas destinadas a contrariar o abandono da atividade agrícola - entre as quais avultam as medidas da Política Agrícola Comum (PAC) - não têm surtido o efeito desejado. 0 que não surpreende, isto se se pensar que qualquer medida com esta finalidade tende a ser, na prática, contraditória com os princípios fundamentais da própria PAC, sobretudo depois da reforma de 1992. Como poderia a aposta na limitação da oferta de bens agrícolas, suportada na generalização de limites à produção, na redução dos preços de garantia e na generosa disponibilização de verbas para a retirada de terras e a cessação da atividade, típica da PAC, não redundar na inviabilização económica de um grande número de explorações agrícolas, em particular das explorações de menor dimensão, mais fragmentadas e menos produtivas?

10 Nestes casos, qualquer apoio à manutenção da atividade tende a ter um peso económico irrisório. Com efeito, o que a avaliação destas medidas constata é que os montantes atribuídos dificilmente melhoram de forma substantiva o rendimento dos agricultores, porquanto o seu valor fica geralmente muito abaixo das despesas adicionais ou perdas de rendimento resultantes da observância dos compromissos previstos pelas medidas. Mesmo no caso das ajudas diretas, que não implicam o cumprimento de compromissos demasiado exigentes, os montantes atribuídos tendem a falhar no objetivo de desincentivação do abandono da atividade. Este facto é particularmente evidente nas regiões de minifúndio, onde as ajudas médias são bastante reduzidas (em 2000, a ajuda média por exploração foi, no Entre Douro e Minho, de cerca de 550 euros; no Alentejo, foi de 3600 euros) (Alves, 2003).

11 Para o Grupo de Trabalho Agroambiental criado no dealbar do milénio pelo Ministério da Agricultura, Desenvolvimento Rural e Pescas e pelo Ministério do Ambiente e Ordenamento do Território para avaliar o impacto do abandono da atividade agrícola, este fenómeno só poderia vir a ser sustentadamente contrariado se a viabilidade das explorações pudesse ser efetivamente assegurada (Alves, 2003). Ora, para que tal fosse 
possível, seria necessário apostar de forma decidida no redimensionamento das explorações, em especial no Noroeste e no Centro do país, regiões onde o risco de abandono da agricultura era - e continua a ser - mais elevado (precisamente pela reduzida dimensão física e económica da esmagadora maioria das unidades agrícolas). A principal proposta do estudo publicado em 2003 pelo supramencionado Grupo de Trabalho apontava, por isso, para a criação de uma estrutura técnica exclusivamente vocacionada para o apoio às iniciativas de redimensionamento das explorações, fossem elas iniciativas de emparcelamento, integração de parcelas abandonadas em explorações cujos produtores pretendessem aumentar a superfície cultivada, fixação de jovens agricultores ou florestação.

Indispensável à viabilização das explorações seria também o reconhecimento da "multifuncionalidade" das unidades agrícolas e do seu papel decisivo do turismo" (associado à natureza, à gastronomia e às produções de qualidade) e, em geral, na "dinamização do tecido económico" (não agrícola) dos territórios rurais (Alves, 2003). 0 princípio na base desta nova forma de encarar a atividade agrícola é o de que o desenvolvimento rural não passa só - nem talvez principalmente - pelo desenvolvimento da agricultura, mas impõe antes a rentabilização das "novas oportunidades" que as transformações nas procuras urbanas dos espaços rurais hoje colocam ao dispor dos agricultores.

O princípio da multifuncionalidade do espaço rural, a que o estudo de 2003 dá eco, na senda do discurso subjacente à reforma da PAC de 1992 e às propostas da Agenda 2000 para o "desenvolvimento rural", é retomado e amplificado num estudo publicado três anos depois, em janeiro de 2006, por investigadores da Universidade de Évora, sob os auspícios de um protocolo assinado entre esta instituição de ensino e o Ministério da Agricultura, com vista à elaboração de uma tipologia de áreas rurais e à promoção de ações de combate ao abandono da atividade agrícola e do espaço rural (Correia, 2006).

primeiro estudo citado refletia já algumas das transformações que se vinham verificando nas representações dominantes sobre a atividade agrícola e o espaço rural, o estudo de 2006 traduz claramente a incorporação desta nova forma de perspetivar a "ruralidade". Na verdade, ocupam agora menos espaço as propostas de reconfiguração das estruturas fundiárias e de modernização técnica e organizacional das explorações; perante a intensidade do fenómeno de abandono da atividade agrícola, atestada por diversos indicadores estatísticos, ganha peso a tese da "disjunção entre o rural e o agrícola". Responsáveis político-administrativos e especialistas coincidem no diagnóstico do problema e na forma de garantir a sua superação: dada a aparente irreversibilidade do declínio da agricultura tal como a conhecemos, o rural está obrigado a diversificar as suas funções. Abre-se, assim, lugar a uma alteração de fundo na avaliação do papel dos espaços rurais na organização dos territórios e, consequentemente, na própria conceptualização das relações entre cidade e campo.

No estudo da Universidade de Évora - e apesar do título escolhido: Estudo sobre o Abandono em Portugal Continental -, o enfoque na ideia de multifuncionalidade do espaço rural leva os autores a sugerirem a substituição da noção de "abandono", habitualmente eivada de um certo "fatalismo", pela noção de "dinâmica territorial", que visa dar conta da existência de níveis diferenciados de dinamismo de ocupação do espaço, dinamismo do setor agrícola e dinamismo socioeconómico das comunidades. De acordo com os autores do estudo, pode haver dinâmica de abandono da atividade agrícola e, ao mesmo tempo, 
dinâmica de substituição da agricultura por novas atividades ou mesmo manutenção da agricultura por via das suas "funções não produtivas" (Correia, 2006).

Segundo esta visão pós-produtivista da agricultura, as funções não produtivas da atividade são externalidades da função de produção que, todavia, podem tornar-se mais importantes do que esta, dada a atual fraca rentabilidade de grande parte das produções agrícolas e os significativos acréscimos de rendimento que podem ser obtidos através da diversificação funcional da agricultura.

O novo papel do setor agrícola na organização do espaço rural, conclui-se, não só abre novas perspetivas à atividade, ao justificá-la para além da sua função "meramente produtiva" (cuja viabilidade aparece resumida, cada vez mais, às produções ditas "especializadas", "biológicas" e "de qualidade"), como permite convocar novos atores para o processo de desenvolvimento rural, em resultado do alargamento das funções consignadas a estes territórios.

Neste contexto, os agricultores são "convidados a 'protagonizar as dinâmicas do território', evoluindo para empresários rurais de atividades diversificadas, acrescentando à sua vocação produtiva tradicional uma componente de atividade e iniciativa centrada numa nova oferta de bens e serviços" (Neves, 2008).

\section{Uma operação de "alquimia simbólica"?}

19 Num artigo publicado na revista Économie rurale, Nicole Mathieu sistematiza e discute, a partir do caso francês - caso particularmente relevante, por corresponder ao "centro" da agricultura europeia (pelo menos da agricultura europeia pós-PAC) e, por isso, constituir o principal polo de produção ideológica de discursos sobre a "atividade agrícola" e o "mundo rural" -, as transformações recentes nas representações dominantes sobre a ruralidade e as relações cidade-campo (Mathieu, 1998).

Destacando a ligação entre o declínio da importância económica e social da atividade agrícola em França e a mudança de conteúdo a que os discursos sobre o rural assistiram na década de 1990, Mathieu fala na consolidação de uma ideologia de ruralidade assente nas noções de "património", "paisagem", “ambiente" e "espaço natural" - um rural essencialmente não produtivo, portanto, em que o papel da agricultura é, sobretudo, o de "atividade gestionária da natureza" (Mathieu, 1998: 13).

21 A esta mudança nas representações dominantes sobre a ruralidade corresponde, inevitavelmente, uma mudança nas representações em torno das relações cidade-campo. Perante a consolidação de uma certa ideia de "crise urbana" (ou "crise do modo de vida urbano"), o rural emerge como "ponto de fuga", espaço de refúgio face aos "males da cidade" e fator de equilíbrio e sustentabilidade ambiental e territorial, para não dizer de "equilíbrio pessoal", "físico e psíquico". Como noutras alturas, o rural define-se essencialmente por oposição ao urbano, mas a visão tradicional da relação entre cidade e campo, assente nos conceitos de desigualdade, antagonismo, dominação (do segundo pela primeira), vai paulatinamente sendo substituída, sugere Mathieu, por um modelo de relação em que a "complementaridade" se torna a palavra-chave. A tónica centra-se agora, cada vez mais, na questão da "mobilidade", cujo crescimento é encarado como condição fundamental do estreitamento das relações entre populações urbanas e populações rurais e da consequente promoção da complementaridade entre cidade e campo. Ao proporcionar a convergência entre os sistemas de referências simbólicas 
tipicamente "rurais" e os sistemas de referências simbólicas tipicamente "urbanos", o crescimento da mobilidade estará, segundo Nicole Mathieu, a contribuir para a consolidação de uma visão mais "pacífica", mas também mais "complexa", das relações cidade-campo e para uma diminuição do hiato entre as representações dominantes acerca do tema e a realidade das dinâmicas socioterritoriais recentes (Mathieu, 1998: 19-20). Apesar de ser uma sistematização útil do "estado da arte", a leitura que Nicole Mathieu faz das transformações a que a noção de ruralidade tem sido sujeita nos últimos tempos falha no que seria talvez mais interessante do ponto de vista sociológico, que seria a objetivação dos processos sociais na génese da mudança ideológica verificada.

Como a maioria dos autores que se vem debruçando sobre este tema, Mathieu concorda que o declínio da importância económica e social da agricultura na Europa está a impor um consenso em torno da inevitabilidade da aposta na multifuncionalidade dos espaços rurais e na diversificação do papel dos agricultores. Sem poder socorrer-se da atividade agrícola, outrora fundamento da organização socioeconómica camponesa, a viabilidade dos territórios rurais passa a estar dependente da capacidade que estes demonstrem para gerar as "novas ofertas" capazes de responder às "novas procuras". o que Mathieu não explicita é que problemas aparentemente "irreversíveis" como o abandono da atividade agrícola - apresentados geralmente sem referência a quaisquer responsáveis (a não ser, talvez, a "concorrência internacional" ou a "evolução dos mercados"...) e sem alternativa senão a que é proposta como única solução realista - são, na verdade, construções políticas - ou, se preferirmos, efeitos do funcionamento de mercados, como os mercados de bens agrícolas, cuja estruturação decorre largamente da aplicação de medidas de política que traduzem, por um lado, o estádio das relações e os resultados das lutas no interior dos campos económico e político (entre protecionistas e liberais, entre agriculturas - e Ministérios da Agricultura - nacionais, entre multinacionais do setor agrícola, entre estas e os produtores tradicionais, etc.) e, por outro lado, as lutas entre grupos sociais pela imposição da visão "legítima", consentânea com os seus interesses, sobre o modo como os espaços rurais devem ser apropriados e utilizados.

24 A análise do caso europeu (e, dentro deste, da situação particular do nosso país) é particularmente útil ao esclarecimento do que acaba de se afirmar. Na Europa, sob os auspícios da PAC, as medidas que direta ou indiretamente contribuíram e contribuem para a inviabilização de vastos sectores da atividade, sobretudo nos países onde a agricultura tradicional predomina e onde mais insistentemente se tem incentivado a retirada de terras e a abertura de fronteiras à entrada de bens agrícolas, fornecem agora a solução “inevitável” para o problema que elas próprias geraram ou ajudaram a gerar. Verdadeira "operação de alquimia simbólica", como lhe chamaria Gérard Mauger", a passagem para uma visão pós-produtivista, pós-agrícola, do rural tende a promover a amnésia da génese política do próprio declínio da agricultura, aparecendo, por conseguinte, aos olhos de todos, como natural, inevitável, autoevidente. Se a agricultura “ não dá", o que haveremos de fazer senão agarrarmo-nos ao que "pode dar"?

26 A verdade, contudo, é que a agricultura portuguesa não se confronta com problemas decorrentes de produção excedentária ou de ausência de possibilidades de escoamento de produtos, a não ser pontualmente e em certas produções. Basta pensar na crónica situação deficitária da balança comercial agrícola do país para concluir que haveria margem de manobra para uma aposta decidida no "rural agrícola"5. Todavia, como membro da União Europeia, Portugal não ficou à margem, bem pelo contrário, do sistema 
de quotas, da redução dos preços de garantia dos produtos, das limitações à produção animal, das medidas de set aside, etc.

Por outro lado, a "desagriculturização" da representação dominante do rural tende a gerar indiferença face aos problemas dos agricultores e, em geral, dos grupos sociais cujo modo de vida permanece direta ou indiretamente ligado ao setor agrícola - categorias sociais agora "residuais", quase exóticas, reminiscências de um passado económico e social cujo desaparecimento se tornou (foi tornado?) inevitável.

\section{A nova ideologia do rural e o espírito do neoliberalismo}

A mudança ideológica representada pela passagem da representação do rural enquanto "espaço agrícola" à representação do rural enquanto "território multifuncional", passagem tornada "inevitável" pelo abandono agrícola tornado "inevitável", parece corresponder, entretanto, à inauguração, nas economias contemporâneas, de uma nova etapa de penetração do capitalismo nos campos, etapa estruturada em torno de duas modalidades fundamentais de apropriação capitalista do espaço rural. Uma, minoritária, corresponde à aposta na reconversão da atividade agrícola, através da modernização dos processos produtivos e da opção por produções especializadas, vocacionadas sobretudo para nichos de mercado cuja procura se estrutura em torno dos princípios da "qualidade" e "diferenciação". Outra, predominante, é a que se funda na visão pós-agrícola do rural e no princípio da multifuncionalidade destes territórios. "Nova oportunidade" - ou até, como por vezes se ouve, "única oportunidade" - de desenvolvimento dos territórios rurais, a multifuncionalidade do rural significa a multiplicação das atividades e do número de agentes económicos (locais e não locais) que nele podem figurar e, nesse sentido, representa o alargamento das formas de apropriação e "rentabilização" deste espaço abandonado ou em vias de abandono ${ }^{6}$.

Estas novas formas de aprofundamento da presença capitalista nos campos traduzem aquela que é considerada por muitos autores como uma das características fundamentais do neoliberalismo, sobretudo em anos mais recentes, a saber, o seu carácter difusivo, isto é, a sua extraordinária capacidade de alastramento geográfico e de penetração nos mais diversos redutos da vida económica e social, capacidade potenciada invariavelmente por inovações ideológicas que visam a consolidação de imaginários económicos tendencialmente hegemónicos (Pierre Bourdieu chamar-lhes-ia "doxas"), os quais adquirem força constitutiva no mundo material sempre que são institucionalizados e incorporados com sucesso pelos agentes sociais. A convergência semântica entre a nova representação dominante de ruralidade e o discurso do capitalismo neoliberal, visível no recurso a termos comuns como "flexibilização", "diversificação", "multifuncionalidade", "adaptação" (à procura), "especialização" ou "competitividade", não pode, neste sentido, ser considerada uma coincidência, mas deve antes ser compreendida como decorrência da difusão do imaginário económico tendencialmente hegemónico associado ao neoliberalismo.

30 A neoliberalização dos campos representada por algumas destas novas formas de apropriação económica do espaço rural (construção de residências secundárias, turismo rural e de habitação, reabilitação de tradições e festividades, parques temáticos, festivais gastronómicos, percursos pedestres, atividades radicais) tem sido impulsionada, 
entretanto, em grande medida, pelo Estado, cuja presença no mundo rural se tem consolidado tanto ou mais que a do mercado. Sob o signo da PAC, o nosso país assistiu, ao longo das duas últimas décadas, a um reforço assinalável da proatividade das políticas públicas direcionadas para o "desenvolvimento rural" e a um alargamento da regulação estatal a domínios - como a forma de utilização das terras, as opções em matéria de produção e de organização dos métodos e ritmos de trabalho, os mercados de trabalho agrícolas ou até, imagine-se, as práticas de transmissão sucessória das explorações familiares - outrora exclusivamente subordinados à lógica de estruturação da economia e modo de vida camponeses.

31 Ao criar condições favoráveis à materialização de um modelo de desenvolvimento assente no princípio da multifuncionalidade dos territórios rurais, por via do aprofundamento do seu papel (des)regulador, o Estado favorece objetivamente a diversificação e intensificação da apropriação capitalista dos campos. Tal articulação entre Estado e apropriação capitalista do espaço (rural ou urbano) constitui, segundo vários autores, outro dos traços distintivos do neoliberalismo7.

32 A forma a-histórica e eufemizada como a nova ideologia do rural se apresenta, como se de uma decorrência lógica, incontestável, do irreversível abandono agrícola se tratasse, como se a ação estatal nada tivesse que ver com a sua constituição e com o que lhe está a montante, como se não fosse resultado de um trabalho de imposição de uma representação do mundo conforme aos interesses de determinados grupos sociais, gera um efeito de ecrã que faz com que a maior parte dos especialistas que se debruçam (tanto na esfera político-administrativa, como na esfera académica) sobre a temática das funções que hoje devem caber ao mundo rural dispense pouco tempo à análise crítica da génese social dos conceitos em que assenta a perceção e a representação dominante daquele mundo. Por outras palavras, o que acontece é que estes especialistas tendem a não objetivar as condições sociais que tornaram não só possível, como necessária a "multifuncionalização" dos territórios rurais "desagriculturizados".

33 Por isso, o que Nicole Mathieu vê, porventura algo ingenuamente, como uma tendência para a "pacificação" da visão dominante acerca das relações cidade-campo, resultado da revalorização simbólica e funcional dos espaços rurais, cada vez mais contrapostos aos (ou complementares dos) espaços urbanos e suburbanos "em crise", e da aproximação entre as hierarquias de valores de citadinos e aldeãos, crescentemente unidos por uma aparente complementaridade de necessidades e interesses, pode bem ser visto como o triunfo de uma nova e particularmente eufemizada - logo especialmente poderosa forma de dominação do espaço social rural pelo espaço social urbano. Se os campos são agora, fundamentalmente, espaços "não produtivos" (pense-se, desde logo, nas implicações deste termo e na forma como os camponeses, se pudessem, devolveriam ao remetente tal "injúria"...), pontos de "refúgio" para os que pretendem escapar dos "males urbanos", não continuará o seu desenvolvimento subordinado aos princípios do modelo de desenvolvimento prescrito pelo mundo urbano dominante? Apesar de abandonarem as suas funções enquanto produtores de bens alimentares e, eventualmente, enquanto fornecedores de força de trabalho para o crescimento urbano-industrial, não continuarão os camponeses e os seus filhos, agora "protetores da natureza", "guardiães da paisagem", representantes da "tradição" e dos modos de vida "autênticos", dominados na produção da sua imagem social e, consequentemente, da sua identidade social?

Colocadas perante um cenário sem alternativas "realistas", confrontadas com uma objetivação que lhes anuncia o que lhes cabe ser, às populações rurais, designadamente 
aos seus segmentos dominados - e, em particular, aos camponeses, essa "classe-objeto" incessantemente convidada a tomar sobre si própria o ponto de vista dos outros, como diria Bourdieu (1977), não restam, de facto, grandes hipóteses senão participar mais ou menos empenhadamente nas estratégias políticas e económicas de reconfiguração dos seus espaços de origem - estratégias a cuja génese permanecem, todavia, geralmente alheios e cuja rejeição, a acontecer, corresponderia, muito provavelmente, a um inevitável definhamento social ${ }^{8}$.

Apresentada como "inevitável", mas não como "fatal", antes como "oportunidade" facilmente transformável em "vantagem competitiva", a reorganização do mundo rural prescrita pelo princípio da multifuncionalidade que está no cerne da conceção hoje dominante de ruralidade tem todas as propriedades de uma solução sem vencidos: com a diversificação das funções consignadas aos territórios rurais, ganham as populações urbanas, que podem finalmente encontrar nestes espaços as comodidades necessárias à recuperação da "tranquilidade perdida" ou ao usufruto de momentos de diversão e enriquecimento cultural, e ganham as populações locais, que beneficiarão, também elas, dos investimentos realizados, passando a ter ao seu dispor novas infraestruturas, equipamentos e, sobretudo, empregos e fontes de rendimento até então inexistentes ${ }^{9}$.

A realidade, porém, é que, tal como as reorganizações e exigências que, no passado, se colocaram ao mundo rural, também a reorganização e as exigências previstas pela nova ideologia da ruralidade, que tem o "abandono agrícola" como pretexto e a "multifuncionalidade" como mote, são impostas a partir do exterior, isto é, do espaço social urbano ou, para sermos mais precisos, do espaço social ocupado pelas classes dominantes - que maioritariamente se radicam nos centros urbanos, mas que também podem ser encontradas nos meios rurais, onde não deixarão de partilhar com as suas congéneres urbanas uma visão tendencialmente comum acerca do modo como devem (re)organizar-se os territórios (com a vantagem de poderem colher diretamente os benefícios económicos decorrentes da rentabilização do seu património, fundiário designadamente).

Levados pela lógica dos seus interesses específicos, os agentes produtores e divulgadores desta nova ideologia da ruralidade - membros das classes dominantes ou das "classes médias urbanas" entre os quais avultarão certamente muitos intelectuais "bem intencionados" - assumem o papel de veículos de legitimação local da tendência transnacional de diversificação das formas de apropriação capitalista do espaço rural (tendência de que são, de resto, beneficiários) - e assim reproduzem, sob formas renovadas e particularmente eficazes, porque impostas como inevitabilidades, com a força do que é dito com autoridade, a autoridade de quem sabe que é assim porque "tem de ser", a dominação material e simbólica do espaço social rural e das suas populações, ainda e sempre privadas da possibilidade de definir e controlar a sua própria identidade social e o seu projeto de futuro. 


\section{BIBLIOGRAFIA}

ALVES, António Lobo (coord.) (2003), o Abandono da Actividade Agrícola, Lisboa: Ministério da Agricultura, Desenvolvimento Rural e Pescas/Ministério do Ambiente e Ordenamento do Território.

BOURDIEU, Pierre (1977), “Une classe objet", Actes de la recherche en sciences sociales, n.ำ17-18: 2-5.

CORREIA, Teresa Pinto (coord.) (2006), Estudo sobre o Abandono em Portugal Continental. Análise das dinâmicas da ocupação do solo, do sector agrícola e da comunidade rural. Tipologia de Áreas Rurais, Évora: Departamento de Planeamento Biofísico e Paisagístico da Universidade de Évora.

GPP/MAMAOT [Gabinete de Planeamento e Políticas do Ministério da Agricultura, do Mar, do Ambiente e do Ordenamento do Território] (2012), Programa de Desenvolvimento Rural 2014-2020 Documento de Orientação, Lisboa: GPP/MAMAOT.

GPPAA/MADRP [Gabinete de Planeamento e Política Agro-Alimentar do Ministério da Agricultura, Desenvolvimento Rural e Pescas] (2006), Agricultura Portuguesa. Principais indicadores 2005, Lisboa: GPPAA/MADRP - Divisão de Divulgação e Relações Públicas.

MATHIEU, Nicole (1998), "La notion de rural et les rapports ville/campagne en France: les années quatre-vingt-dix", Économie rurale, n. 247: 11-20.

MAUGER, Gérard (2001), "Les politiques d'insertion. Une contribution paradoxale à la déstabilisation du marché du travail”, Actes de la recherche en sciences sociales, n.․ 136: 5-14.

NEVES, António Oliveira das (2008), "Multifuncionalidade e renovação do trabalho agrícola", Anuário Janus 2008, disponível em http://janusonline.pt/2008/2008_4_2_2.html [acedido em 14 de dezembro de 2012].

PECK, Jamie, TICKELL, Adam (2002), “Neoliberalizing space”, Antipode, vol. 34, n. 3: 380-404.

PINTO, José Madureira, QUEIRÓS, João (2010), Ir e Voltar. Sociologia de uma colectividade local do Noroeste Português, Porto: Edições Afrontamento.

QUEIRÓS, João (2010), “Transformação e resistência da agricultura e da economia camponesa”, in José Madureira Pinto e João Queirós (2010), Ir e Voltar. Sociologia de uma colectividade local do Noroeste Português, Porto: Edições Afrontamento.

WEBER, Rachel (2002), "Extracting value from the city: neoliberalism and urban redevelopment", Antipode, vol. 34, n. 3 : 519-540.

\section{NOTAS}

1. Este artigo retoma uma reflexão iniciada no âmbito do projeto $\mathrm{POCI} / \mathrm{SOC} / 58668 / 2004$, Transformações sociais numa coletividade local do Noroeste português, financiado pela Fundação para a Ciência e a Tecnologia e sediado no Instituto de Sociologia da Universidade do Porto, sob coordenação científica de José Madureira Pinto. Em Pinto e Queirós (2010) podem encontrar-se alguns dos principais resultados desta pesquisa, incluindo informação exaustiva sobre transformações da agricultura e do espaço social rural no Noroeste português ao longo das últimas décadas, para além de diversas referências bibliográficas adicionais sobre este tema. 
2. Os dados mencionados nesta secção são dos Recenseamentos Agrícolas realizados entre 1968 e 2009 e dos Recenseamentos Gerais da População realizados entre 1960 e 2011. Toda a informação está devidamente organizada e pode ser consultada online no Portal do Instituto Nacional de Estatística, em http://www.ine.pt. Uma análise detalhada das séries cronológicas de dados de que aqui se oferecem alguns números pode ser encontrada em Queirós (2010).

3. Ver, por exemplo, o artigo (não assinado) "Pais devem voltar a incentivar filhos a regressar à agricultura", publicado no Jornal de Notícias de 2 de junho de 2011, ou o artigo de Filipa Dias Mendes, "Ministro da Economia defende 'regresso à agricultura e à indústria", publicado no jornal Público de 28 de fevereiro de 2013.

4. Gérard Mauger usa a expressão para se referir à mudança ideológica que se vem verifi cando recentemente a propósito das formas de tratamento social do desemprego. Em concreto, Mauger refere-se à passagem da noção de "desemprego" à de "empregabilidade" e aos novos instrumentos de intervenção social que a ela estão associados, que significam, para o autor, uma redefinição - com efeitos potencialmente perversos - da visão legítima do desemprego e do desempregado. Desviando a atenção das estratégias de gestão neoliberais (despedimentos, deslocalização de empresas, precarização das relações contratuais), dos efeitos de uma massificação escolar não acompanhada por uma elevação generalizada do nível de qualifi cação dos postos de trabalho e dos níveis de exigência do tecido produtivo, enfim, demitindo-se da crítica do modelo de desenvolvimento socioeconómico dominante, a passagem para a noção de "empregabilidade" coloca a tónica nas "vítimas" e nos seus "défices", o que representa uma inversão do modo de perspetivação do problema do desemprego e, na verdade, a elisão da sua génese social e do seu carácter estrutural (ver Mauger, 2001).

5. De acordo com dados apresentados em maio de 2006 pelo Gabinete de Planeamento e Política Agroalimentar do Ministério da Agricultura, do Desenvolvimento Rural e das Pescas, o saldo comercial do complexo agroflorestal português foi, em 2003, de -2661 milhões de euros. Mais de metade deste montante ( -1573 milhões de euros) correspondeu ao saldo comercial do setor da agricultura e silvicultura (ver GPPAA/MADRP, 2006: 70). Dados mais recentes revelam uma ligeira atenuação deste défice, para valores na ordem dos dois mil milhões de euros, fruto do comportamento muito positivo da fileira florestal, que viu crescer os seus excedentes de cerca de mil milhões de euros, em 2006, para valores rondando os 2500 milhões de euros, em 2011. Em contraciclo com esta evolução, o agroalimentar viu o seu défice aumentar para valores superiores a quatro mil milhões de euros (dados provisórios relativos a 2011; ver GPP/MAMAOT, 2012: 8).

6. Tanto nos campos como nas cidades, a "obsolescência" tornou-se "o álibi neoliberal para a destruição criativa e, por isso, um importante elemento dos atuais processos de acumulação espacializada de capital" (WEBER, 2002: 532). Nos campos, as velhas casas agrícolas dão belos "chalés" para turismo de habitação; nas cidades, os edifícios obsoletos podem ser transformados em condomínios privados, antigos blocos de escritórios podem tornar-se lofts ou estúdios, armazéns e fábricas abandonadas podem ser demolidas para incrementar a oferta de área edificável ou para disponibilizar espaço para projetos de desenvolvimento urbano de larga escala. A "obsolescência" das formas espaciais desloca para essas mesmas formas o ónus das intervenções tendentes à sua reabilitação ou reconfiguração, elidindo o papel dos agentes (políticos, económicos, imobiliários) empenhados na sua promoção - papel que, em muitos casos, foi decisivo para que se chegasse ao estado de "abandono" e "obsolescência" entretanto avançado como pretexto para a intervenção. Fenómenos de génese social são reduzidos assim ao estatuto de assuntos de aparência meramente técnica.

7. Ver, a propósito, a esclarecedora síntese de Peck e Tickell (2002). Com as devidas distâncias, a análise que estes autores fazem do processo de "neoliberalização" do espaço urbano pode ser transferida para o estudo das propostas que hoje se colocam aos espaços rurais. Não é, afinal, a pressão para a diversificação das funções dos territórios rurais e para a sua adaptação às "novas procuras urbanas" uma estratégia, o mais das vezes conduzida pelas instâncias estatais, de 
"gentrificação" - idêntica, neste sentido, à que subjaz à maioria das propostas de revitalização dos espaços degradados e abandonados do centro das cidades visando a respetiva apropriação por grupos sociais cada vez mais afluentes?

8. Como sublinha Bourdieu (1977: 4), “a folclorização, que coloca o campesinato no museu e que converteu os últimos camponeses em guardiães de uma natureza transformada em paisagem para citadinos, é o acompanhamento necessário da desapossessão e da expulsão. São, com efeito, as leis do lucro diferencial, a forma fundamental do lucro de distinção, que atribuem aos camponeses as suas reservas, onde eles terão todo o tempo livre para cantar e dançar as suas modas e gavotas, para grande satisfação de etnólogos e de turistas citadinos, e assim a sua existência será durante muito tempo económica e simbolicamente rentável".

9. Em Neves (2008) é apresentada uma lista de "profissões em emergência" no território rural "multifuncional". Integram-na as seguintes profissões: "Animador rural"; "Consultor comercial"; "Consultor de marketing turístico"; "Controlador de qualidade dos produtos agrícolas"; "Empresário-gestor de empresa de prestação de serviços"; "Fiscal de boas práticas agrícolas"; "Gestor de montados"; "Gestor de recursos hídricos"; "Gestor de produtos agrícolas e/ou pecuários"; "Gestor de propriedades rurais"; "Guia agroturístico"; "Monitor turístico"; "Operador agroturístico"; "Promotor de eventos no espaço rural"; "Técnico de energia"; "Técnico de marketing territorial"; "Técnico de sistemas de rega"; "Técnico de turismo"; "Vigilante da natureza". A esta lista segue-se uma outra, correspondente às "profissões em crescimento", mas que repete algumas das "profissões em emergência: "Agricultor biológico"; "Apicultor"; "Empresário-gestor de unidade de turismo rural"; "Empresário-produtor florestal"; "Fiscal de rega"; "Agricultor" [sic]; "Operador agrícola"; "Operador de máquinas e equipamentos"; "Prestador de serviços agropecuários"; "Sapador florestal"; "Técnico de qualidade e segurança alimentar"; "Trabalhador florestal" "Técnico/consultor agropecuário e florestal - assistência e apoio técnico"; "Técnicos de manutenção de máquinas e equipamento agrícola"; "Tirador de cortiça".

\section{RESUMOS}

Partindo da análise de alguma informação sobre a evolução da agricultura em Portugal, o que este artigo propõe é uma reflexão crítica muito breve acerca das transformações que a noção de "ruralidade" tem vindo a conhecer e do papel que, no quadro dessas transformações, é hoje consignado às populações locais, designadamente àquelas que mantêm relação com a atividade agrícola, pelo discurso da "multifuncionalidade", que nos últimos anos se vem assumindo como narrativa dominante no que ao "futuro", "viabilidade" e "desenvolvimento sustentável" dos territórios rurais diz respeito.

Returning to a line of reasoning proposed by Pierre Bourdieu in an article originally published in 1977 - a text that has become a classic of sociology, in which the French sociologist discusses the externally determined nature of the production and distribution of images, representations, identities and projects associated with the countryside and farmers - our article presents a very brief critical refl ection on the transformations that, in an increasingly "postagricultural" scenario, the concept of "rurality" has suffered and on the role that, in these transformations, is assigned to local populations, especially those who maintain a relationship with agriculture, through the discourse of "multifunctionality", which in recent years has become the dominant 
narrative regarding the "future", the "feasibility" and the "sustainable development" of rural areas.

Revenant à une ligne de raisonnement proposé par Pierre Bourdieu dans un article initialement publié en 1977 - un texte qui est devenu un classique de la sociologie, dans lequel le sociologue français discute le caractère extérieurement déterminé de la production et de la diffusion des images, des représentations, des identités et des projets associés à la campagne et aux paysans notre article propose une réflexion critique est très brève sur les transformations qui, dans un scénario de plus en plus «post-agricole», la notion de «ruralité» a subi et le rôle que, dans ces transformations, est assigné aux population locales, en particulier celles qui maintiennent une relation avec l'agriculture, à travers le discours de la «multifonctionnalité», lequel dans ces dernières années est devenu la narrative dominant en ce qui concerne au «futur», à la «faisabilité» et au «développement durable» de territoires ruraux.

\section{ÍNDICE}

Palavras-chave: Abandono agrícola, multifuncionalidade, espaço social rural, pós-ruralidade Keywords: agricultural decline, multifunctionality, rural social areas, post-rurality

Mots-clés: déclin de l'agriculture, multifonctionnalité, espaces sociaux ruraux, post-ruralité

\section{AUTOR}

\section{JoÃo QUEIRÓS}

Instituto de Sociologia - Universidade do Porto

jqueiros@letras.up.pt 